\title{
Article
}

\section{Less is More: The Simplification of Characters in Chinese Tra- ditional Opera}

\author{
Jiede $\mathrm{Wu}{ }^{1}$, Yikang Sun ${ }^{2}$ and Rungtai Lin ${ }^{3, *}$ \\ 1 School of Journalism \& Communication, Anhui Normal University, Wuhu City 241002, China; \\ 125082357@qq.com \\ 2 College of Art \& Design, Nanjing Forestry University, Nanjing 210037, China; sunyikang120110@hot- \\ mail.com \\ 3 Graduate School of Creative Industry Design, National Taiwan University of Arts, New Taipei City 22058, \\ Taiwan \\ * Correspondence: rtlin@mail.ntua.edu.tw
}

\begin{abstract}
A simplification of Chinese traditional painting approach was proposed to study whether or not "Less is More" is still truly a design trend. A total of 225 volunteers from a website participated in the study. Through a questionnaire survey and analysis, this study explored the feasibility of "simplified" in comedy. The results show that the proposed approach of "simplification" can be applied to the drama character creation, but the simplification scale needs to be flexibly adjusted according to different topics. For viewers, there is not much recognition and liking for the works that are simplified to the extreme and present symbolization. In future research, the proposed "simplified" approach is needed to adjust and improve for practical use. It also needs more analysis of the differences in cognition of different participants according to the cognitive and communication theories of artistic creation.
\end{abstract}

Keywords: less is more; opera characters; comic creation; simplification; cognitive ergonomics

\section{Introduction}

The concept of 'Less is More' that leads to good design is a phrase adopted in 1947 by architect and furniture designer Ludwig Mies van der Rohe, one of the founders of modern architecture and a proponent of "Less is more" of style [1,2,3]. Consequently, from fine art, architecture, and industrial design, down the way of life, there's almost no form of human expression that has escaped the influence of 'less is more': the notion that a smaller amount of something can be a lot more effective than a large amount or too much of it. The phrase "less is more", it first appeared in an 1855 poem, 'Andrea del Sarto', by Robert Browning [4]. Although its roots can be set as far back as to the Chinese philosophy values of The Book of Changes and principles of "Less is more, more is confusing" [5] (p. 440). That means that the human's potential is limited, so if you take too much, it will become complicated, leading to confusion. But if you ignore the unnecessary things and absorb only the essence, that is when you are genuinely ready and can succeed. In the design field, "less is more" has a global reputation and large-scale impact which are still notable today [6]. Designers around the world have fully followed this trend in the last decade, and the results have been a little more than encouraging (April Studio 2019).

For product design, along with technology progress, in the 1930's, we found that "form follows function"; that is, the appropriate pleasing product form will follow if the product is appropriately designed for its function $[3,7,8]$. This philosophy dominated design concept and technology for manufacturing and marketing. Based on technological progress, product personality can affect users' interaction with and evaluation of a product. Recently, designing "Feeling" into products to present the emotional communication of user experience became a design trend in the 21st century. Design feeling focuses on designing something with not just the end goal in mind, but with the goal of setting up an experiencing and making 
the user feel something as they engage with the device or experience [9]. As a result, "design for feeling" became the key factor for innovative products. In other words, the product must be endowed with an immediate attraction and this therefore renders user perception of innovative product form an important issue for "pleasure" [10,11,12,13]. Does "less is more" still truly in product design trend? Actually, 'less is more' is a cliché but absolutely valid. Minimalism as a design movement is relatively young, having only really come into its own in the late 1960's and early 1970's. In its most stripped-down definition, minimalism is about designers expressing only the most essential and necessary elements of a product or subject by getting rid of any undue and, therefore, unnecessary components and features [14].

Although "less is more" is best applied when talking about good design, these few words of wisdom can be applied to pretty much anything in life. Many studies [15] had indicated that the study of "less is more" was effective in evaluating comprehension of human behavior. For example, according to Norton et al. [15], the less is more effect can be accounted for within the framework of ambiguity and familiarity. Evidences showed that less information leads to greater liking, and more information leads to less liking. Thus, ambiguity leads to liking because of dissimilarity whereas familiarity can breed contempt because of acquiring more information. Thinking about design as a process of "less is more", how the designer's performances are conceived, developed, delivered and received, and how the viewer is attracted, accurately understanding the design and affected by the design have to be studied. Therefore, the purpose of this study is designed to explore how the concept of "less is more" affects design. The results give some explanations for the concept of 'less is more' and finally how to select the right design is discussed.

In the field of art and design creation, "doing subtraction" has traditionally been a difficult but interesting issue $[16,17,18]$. From prehistoric to the present, and from the east to the west, many philosophers, artists, and designers have put forward different opinions around "Doing subtraction during art and design creation". This research combines the above philosophy with the principles of aesthetic in Chinese painting, to propose an approach for comic creation and evaluation criteria, and to simplify the creation of characters in traditional opera. From this, it can be grasped whether the viewer approves of this creation mode and the content and the details they are interested in.

The article is prompted by one of the viewpoints of modern design: "less is more", and explores the feasibility of "simplification" idea through comic creation. The concept of "less is more" is undoubtedly successful when applied to modern design, but whether it applies to other artistic creations requires further discussion. The purpose has the following three points:

1. The purpose of this paper is tantamount to study factors affecting the evaluation of artworks.

2. The purpose of this article is tantamount to explore how comic creation can be used to simplify the character of opera characters, and to study whether the viewer can understand the creator's motivation and ideas.

3. This also shows that the aim of this study is to simplify the application of the philosophy of "less is more, more is confused" in the creation of opera, which deserves further discussion and review.

\section{Literature Review}

\subsection{Visual Features for Icon Design}

In the concept of 'less is more', simplification is the key point. It can be shown from many designs that the designer only knows to do subtraction in the design process, and ignores the subtraction of design elements in order to enhance the meaning of the product. For example, with iconic interface design, the icon designer will face a problem of how to select an appropriate design style for the icon, because icons vary from extremely abstract to representational symbols. Lin (1994) identified three distinguishing features of an object that can be distributed among designers and the users. The three distinguishing features 
of an object, taking the Nautilus as an example are: shape feature, function feature and image feature [19]. The three features are further described as following:

- Shape feature: A shape feature is one that serves as an example for a general class of objects. A shape feature is not an exact copy of a shape of an object, but rather reflects the relevant qualities of an object.

- Function feature: A function feature is used to lead designers to seek structural principles in design for creating their own images. The design results from the function feature involved in a particular action as necessarily as the conclusion of a theorem of geometry.

- Image feature: An image feature attempts to present a concept to a viewer that is apart from the concrete image; its graphic form portrays the perceptual content of an object or concept it represents (Lin 1994). The image feature is not the intention of this design style to show the shape of an object. Inversely, the image feature is intended to convey the image of an object; an image at a higher level of abstraction than the symbol itself.

\subsection{Levels of Stylization}

Meyer et al. [20] defined "Levels of stylization" as the portrayal of useful and essential visual elements of an object relative to the object's identification, and illustrated the five levels of stylization with an apple "object" perceptual content of an object or concept that it represents while others are stylized by shape feature, image feature, or their combinations. Taking Nautilus as an example, the levels of stylization based on the visual features are shown in Figure 1. In each of these visual features, any 'object' can be stylized from a 'real thing' to a 'useful icon' - from shape, image or function feature to representational, abstract, or arbitrary icon [21].

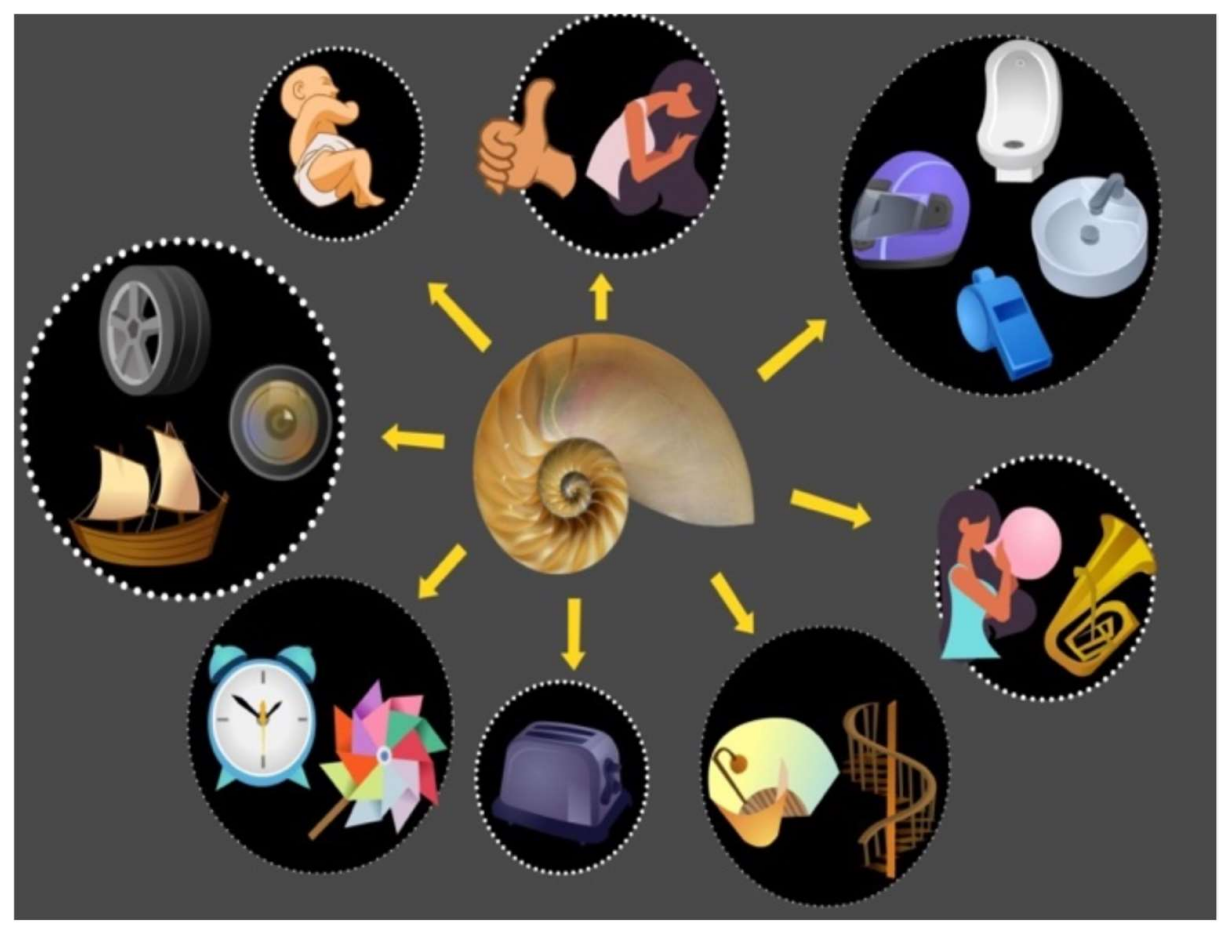

Figure 1. Levels of stylization for Nautilus.

When "less is more" comes to graphic design, simplicity plays a key role in guiding the observer's attention and helping them understand a design. In this multimedia era, information and distraction overflow, our minds and eyes crave simplicity. Simple is 
better than something advanced or complicated. Following the "less is more" rule is critical when designing because the base of graphic design is communication. How is the relationship between the designer and the audience is potentially altered in communication? Before beginning any communication activity, designers want to start with the following question: How can designers create less to deliver more? Can designers take away (even more) to make more impact? If you complicate what you are communicating then your design will never be recognized. The fewer elements there are in the mix, the better the chances that both of these goals will be shared. Design takes the form of imagining and planning the idea that there is more than the visual look of something. While design is at the same time an art and a science, the art of design is in how designers combine visuals and verbal to create an innovative idea that will connect with their audience [22].

However, there is not any common visual vocabulary shared by designers and users. It is sometimes difficult to categorize icons either abstract or representational because an "object" can be stylized over a continuous scale of abstraction. Graphic designers are concerned more with the stylization of an object to a symbol than with its classification as representational or abstract. In principle, any object can be "stylized" or "abstracted".

Actually, there have been very rigorous research work done on the specific topic of simplification. Wang and Hsu [23-24] argued that in the design fields, graphics are often a medium of communication whose goal is to reach mutual understanding. But graphic design is often considered an artistic behavior that is difficult to analyze rationally. They carried out detailed analysis and discussion in two papers. And in the paper, they completed in 2010, they continued their previous research and discussed the relationship between shape features and degrees of graphic simplification [25].

\subsection{Communication Matrix}

As designer and educator Victor Papanek [26] (p. 4) said: "Design is the conscious and intuitive effort to impose meaningful order." In simple language it means that the design should be meaningful, which implies that if we design a product in a way that is easy for users to use and can help them achieve their goals, they will be satisfied and happy [27]. However, whether the audience, can understand the intention of the designer or creator is most worthy of discussion. Although most of the viewers have not received art-related education and training, this does not prevent them from enjoying art work. For example, consider Da Vinci's famous painting Mona Lisa in the Louvre: some people are very fascinated and they have to take a look even if they may be unable to see clearly at a distance. Therefore, because viewers come from different backgrounds and everyone's life experience and aesthetics are different, adopting appropriate modeling semantics in design and comic creation and clearly conveying the artist's intentions and ideas to the viewer is a task that is not easy to complete. In fact, just as for the designer or artist, the process of insuring the viewer's appreciation and interpretation of the work is also a design process, and vice versa.

In general, in the process of design and creation, it is appropriate to adopt a simplified way of thinking, and simplification is the focus and core of it. However, from the designer's point of view, it is a design for subtraction. For users, those elements that are subtracted by the designer can have no impact on their interest and preference for the product. Therefore, for designers and creators there is a need from the perspective of consumers and audiences during the simplified creative process.

Taking design as a process of communication, the relationship between the artist and the audience is potentially altered in social networking. In the social networking era, connection between artist and audience has become increasingly close. For the artworks to be effective in communication, they need to be meaningful, understandable, memorable, etc. In order to evaluate artworks, it is necessary to find the cognitive factors affecting them. The importance of communication studies is shown repeatedly in numerous studies of evaluating artworks. Despite the recognized importance of social interaction between artist and audience, there is no systematic approach to explore it. 
Lin et al. [28] studied factors affecting the evaluation of artworks. Then, these factors are analyzed and examined in order to establish a communication matrix to understand the perceptions of artist and audience. These factors can then serve as a basis for evaluating artworks during the creation stage. The paper proposed an approach combining cognition and communication theory which integrated the three dimensions for evaluating artwork as showed in Table 1 [28].

In contrast with existing evaluation tools, this communication matrix is a multi-dimensional evaluating tool that places the artist and artistically literate citizen's values at the core of the matrix. Its first dimension facilitates the identification of the core values involved in any artwork, including performance, processes and products. Its second dimension facilitates identification of the related theory that may need to be taken into account in assessing the outcome and impact. These include communication theory, mental model and information processing. The third dimension is flexibility, as the matrix can be tailored to the needs and priorities of the different context of the artist, viewer and artworks. It allows relevant measures and indicators of quality and impact to be identified.

Table 1. The communication matrix for evaluating artwork.

\begin{tabular}{|c|c|c|c|c|}
\hline \multicolumn{5}{|c|}{ ARTIST (CODING) } \\
\hline & Performance & Processes & Products & \\
\hline & Inspiration & Ideation & Implementation & \\
\hline \multirow{3}{*}{$\begin{array}{l}\text { Level } \\
\text { C }\end{array}$} & C7-1: Topic and Acknowledgment & C8-1: Thought Provoking & C9-1: Emotional Resonance & \multirow{3}{*}{$\frac{\text { Reflection }}{\text { Affecting }}$} \\
\hline & C7-2: Going beyond Reality & C8-2: Deep Planting & C9-2: Authentic Experience & \\
\hline & C7-3: Affluence in Life & C8-3: Immersion & C9-3: Mental Simpatico & \\
\hline \multirow{3}{*}{$\begin{array}{l}\text { Level } \\
\text { B }\end{array}$} & B4-1: Curiosity Raising & B5-1: Moving Stories & B6-1: Richly Culturally-Loaded & \multirow{3}{*}{$\frac{\text { Realization }}{\text { Accuracy }}$} \\
\hline & B4-2: Desire Exploring & B5-2: Mood Changing & B6-2: Realistic Characteristics & \\
\hline & B4-3: Emotion Stirring & B5-3: Inspiring the Atmosphere & B6-3: Role Identity & \\
\hline \multirow{5}{*}{$\begin{array}{l}\text { Level } \\
\text { A }\end{array}$} & A1-1: Appropriately Captured & A2-1: Well-Paced & A3-1: Well Defined Personalities & \multirow{3}{*}{$\frac{\text { Recognition }}{\text { Attraction }}$} \\
\hline & A1-2 Creative and Clever & A2-2: Touching Plot & A3-2: Skillful and Appealing & \\
\hline & A1-3: Video Effects & A2-3: Sensitive Settings & A3-3: Warm Touching & \\
\hline & Aesthetic & Meaningful & Emotional & \\
\hline & Experience & Experience & Experience & \\
\hline \multicolumn{5}{|c|}{ AUDIENCE (DECODING) } \\
\hline
\end{tabular}

\subsection{Simplification of Chinese Painting Approach}

The construction technique of "leave a blank (such as leave some blanks to indicate "waterfall", "sky and clouds" or "river" in picture.)" is frequently applied in Chinese painting, and its concept is analogous to "less is more". The connotation of emptiness and solidness are two of the key features in the creation process. Thus, simplification is a very important method used by the Chinese painter to create attractive work. By talking about Chinese classical aesthetics of form, spirit and image, this research analyzes and develops the creative concepts of simplicity. "Form" represents the figure of a person, the physical body and the features of a character. "Spirit" represents the mind of a person, which is the core value of life and the inherent spirit of a personality. "Image" is an issue with a long history in Chinese traditional aesthetics which conveys the unique principles of Chinese traditional aesthetics and its aesthetic charm valuing the artistic conception from the perspectives of its functionality and aesthetic tastes of the artists. After studying the related research $[29,30,31]$, this study concluded that simplicity in Chinese painting is not only subtracting the obvious elements but also adding something meaningful, and four skills were identified to simplify in the creation process as a Chinese approach, namely, "Transfer Features to Form", "Transform Features to Spirit", "Reflect Spirit to Semantics, and "Ignore Form to Essence", as shown in Figure 2 compared to the levels of stylization proposed by Meyer et al. [20]. 


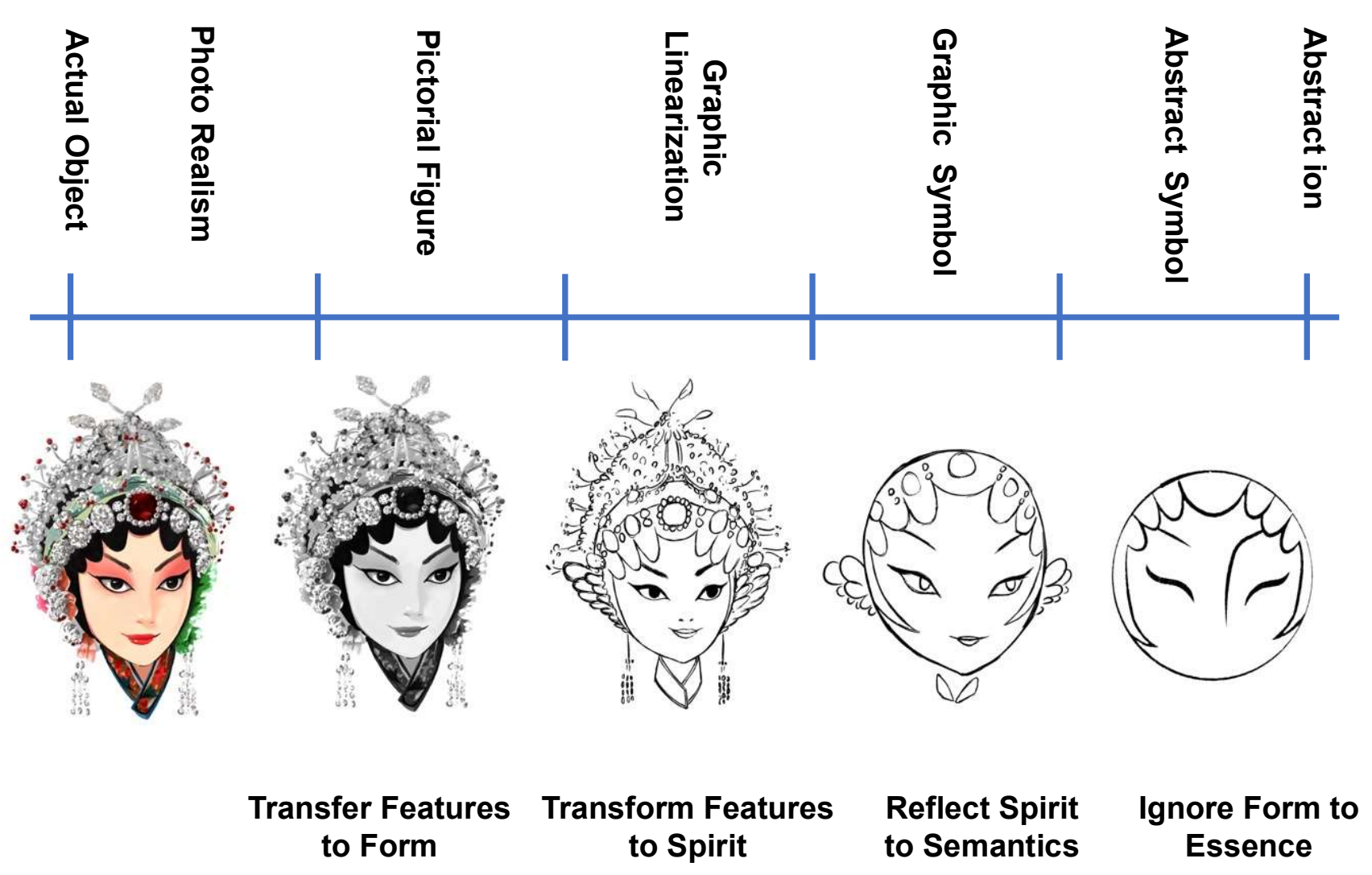

Figure 2. The process of simplification and comparison in the levels of stylization (Source: this study).

The six principles of Chinese painting were established by Xie He in six points to consider when judging a painting from the preface to his book The Record of the Classification of Old Painters written circa 550 and refers to "old" and "ancient" practices. The six elements that define a painting are shown in Table 2 [31] (p. 353). These have been translated over the years by a succession of sinologists with very varying translations [33] (pp. 11-3). "The problem lies, of course, in the terseness of the original Chinese, where each principle is stated in but four characters. ...Each period of Chinese painting has its own special way of interpreting the six principles...their application is fluid, varying according to period and artist. [34]"

Based on the six principles of Chinese painting, and the idea of "less is more", this study proposed the following four guidelines for the creation and evaluation of this study. They are further described as follows:

- Transfer Features to Form. Core thinking is objective depiction and direct expression emphasizing the basis of form and respecting the form of the object. Such a way of manifestation aims to achieve a vivid resemblance with the "form" of the characters.

- Transform Features to Spirit. Generally speaking, form is the carrier of spirit. Without the form, spirit will not be conveyed at all. Form and spirit are in a precedence and subordination relationship. The painters should manifest the inherent essence of a figure and pursue the spirit through the form of painting.

- $\quad$ Reflect Spirit to Semantics. As Xie He said: “Spirit Resonance, or the vitality, and seems to translate to the nervous energy transmitted from the artist into the work. If a painting is without 'spirit resonance', there is no need to look further." Similarly, when comic creation encounters are implied opera elements, it will add some 
semantic effects. The form and spirit of opera will form some symbolic visual images and highlight the implied characteristics of opera culture.

- Ignore Form to Essence. Chinese traditional philosophy is a poetic philosophy and artistic philosophy, pursuing "implication beyond the lines", "image beyond the images" and "purport beyond the tastes". In traditional Chinese aesthetics and philosophy, they often attach great importance to concepts and ignore forms. In this last principle, the focus is on how to outline the character with the simplest lines, while retaining the rich dramatic connotation and spirit behind the character. In short, the form is the simplest and the content is the most abundant.

Table 2. Six principles of Chinese painting by Xie He.

\begin{tabular}{|c|c|}
\hline Principle & Main content \\
\hline Spirit Resonance & $\begin{array}{l}\text { "Spirit Resonance," or vitality, and seems to translate to the nervous energy transmitted from the artist } \\
\text { into the work. The overall energy of a work of art. Xie He said that without Spirit Resonance, there } \\
\text { was no need to look further. }\end{array}$ \\
\hline Bone Method & $\begin{array}{l}\text { "Bone Method," or the way of using the brush. This refers not only to texture and brush stroke, but to } \\
\text { the close link between handwriting and personality. In his day, the art of calligraphy was inseparable } \\
\text { from painting. }\end{array}$ \\
\hline \multicolumn{2}{|c|}{ Correspondence to the Object "Correspondence to the Object," or the depicting of form, which would include shape and line. } \\
\hline$\underline{\text { Suitability to Type }}$ & "Suitability to Type," or the application of color, including layers, value and tone. \\
\hline Division and Planning & $\begin{array}{l}\text { "Division and Planning," or placing and arrangement, corresponding to composition, space and } \\
\text { depth. }\end{array}$ \\
\hline Transmission by Copying & $\begin{array}{l}\text { "Transmission by Copying," or the copying of models, not only from life but also the works of antiq- } \\
\text { uity. }\end{array}$ \\
\hline
\end{tabular}

\section{Method}

\subsection{Research Framework}

Traditional opera and modern comics which have very strong characteristics are two different kinds. There is rigorous denotation in the sensuous performance of traditional opera, and the creation process of contemporary comics has a perceptual connotation. Along with the history, these two kinds of art present their individual artistic characteristics in different ways. The art work can express the customary cultural connotation and modern aesthetic style which is connected with the core spirit of Chinese aesthetics. Therefore, this study refers to the six Chinese classical aesthetic principles in Table 2 to analyze the connotation of traditional opera and build the creative concept of comics. Based on the theory of cognition and communication, first, this study analyzed the features of dramatic characters and the semantic meaning of performing actions. Then, innovative figures of opera comics were created to evaluate the feasible methods and strategies to the creation of dramatic comics.

Three levels of problems are associated with the study of communication: technical, semantic, and effectiveness. The technological level requires getting the viewer's attraction for recognition through his/her senses. The semantic level requires letting the viewer accurately realize the meaning of the message through his/her realization. The effectiveness level concerns the ways in which the viewer is made to take moral reflection through his/her cognizance $[34,35,36]$. Starting with the image formation of the opera and using comics to express the shape and spirit of the characters, Lin [38] proposed the four steps of the creative process -- set a scenario, tell a story, write a script, and create a comicwhich extending the comic creation process of opera elements into a unique creative model called "Ignore Form to Essence". Analysis from the practice of comic creation to achieve the purpose of "Reflect Spirit to Semantics", in order to establish a research framework for comic creation of simplified opera is shown in Figure 3. 


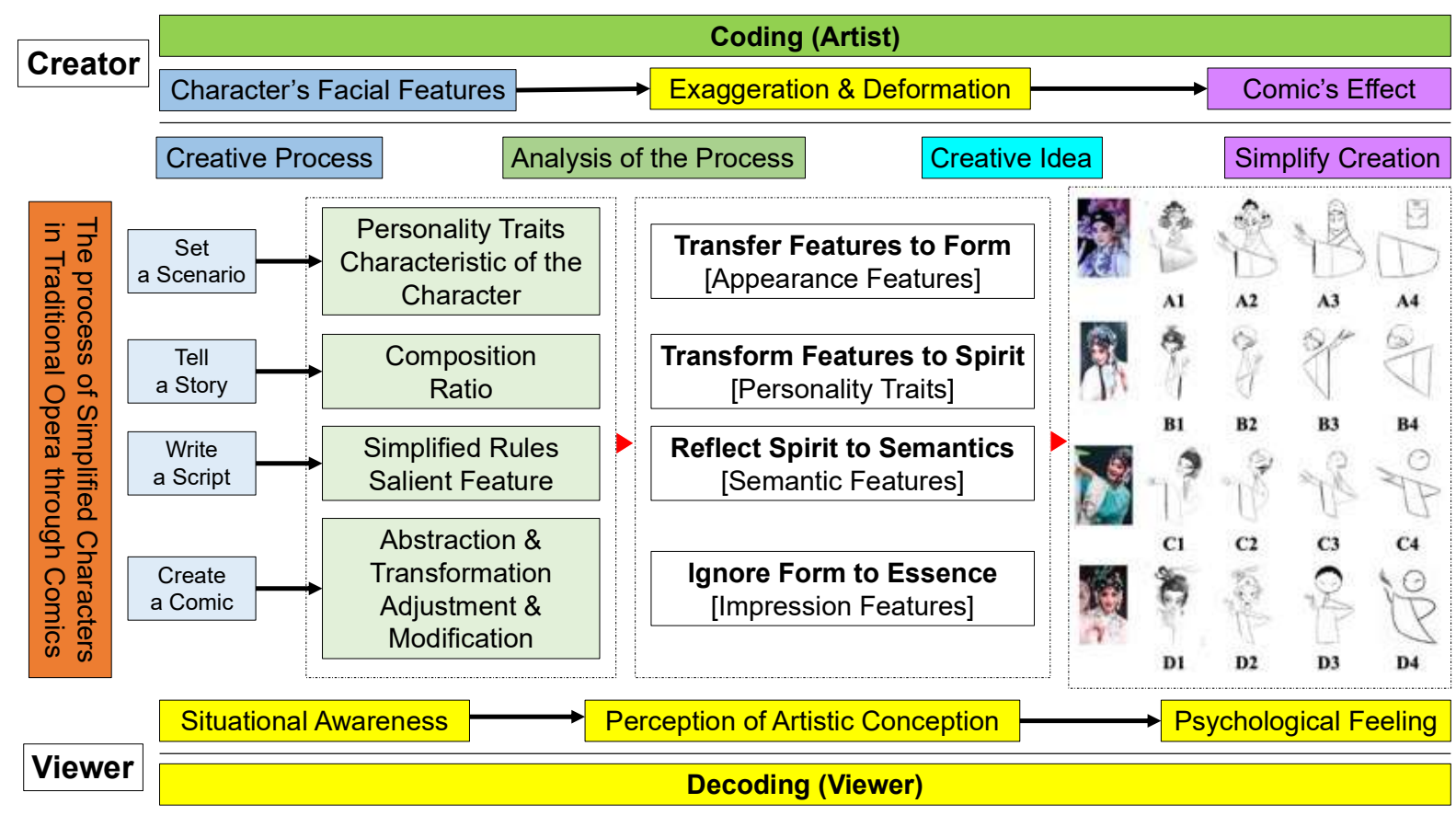

Figure 3. Research framework (Source: this study).

\subsection{Procedure}

The process has been divided into three stages as shown in Figure 4. The first stage mainly discusses the literature, including the creation of comics, the characteristics of traditional opera, and the theory of communication. Based on the above concepts and theories, a creative theory composed of the following four characteristics is constructed: "Transfer Features to Form", "Transform Features to Spirit", "Reflect Spirit to Semantics", and "Ignore Form to Essence".

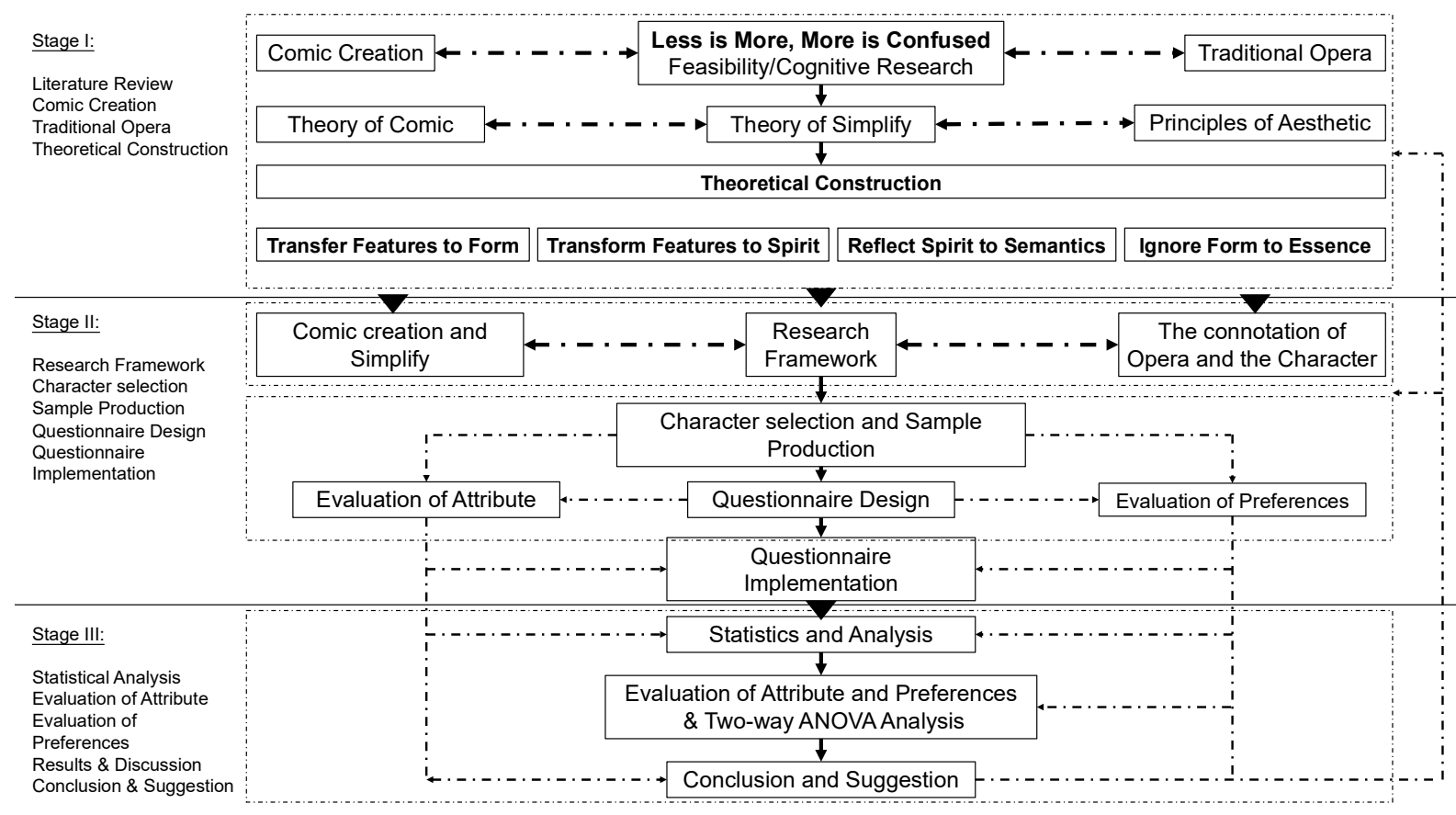

Figure 4. Three stages of research (Source: this study). 
The main content of the second stage is to use comics as a creative method to simplify the creation of characters in traditional opera. Specifically, it is divided into the research framework, selection of personal, sample creation, questionnaire content design, and implementation. As the proverb says: "Follow the rules and make your own way." There are likewise certain methods and procedures for comics to simplify the creation of opera. This article explores how comics simplify the language form of opera from the principles of aesthetics and the regularity of artistic creation. During the creative process, the author keenly grasps the characteristics of the characters in the original image and carries out "transformation" and "simplification" in a targeted manner. The author looks for the elements that best reflect their quality from the expressions, dynamics, clothing, and accessories of the characters in the original image. Next, by imagining and constructing specific stories and situations, the author gradually creates simplified work in order to achieve a harmonious and balanced state, while retaining emotions and cultural connotations.

The third stage focuses on statistical analysis, including the analysis of subjective preferences and attributes evaluation. Finally, make inferences based on the results of the data analysis, summarize the conclusions and make recommendations.

\subsection{Samples}

After historical evolution, four basic types of characters were formed in the opera, called Sheng, Dan, Jing, and Chou, Table 3 shows the main meanings of the above four roles [39,40,41]. Among them, Dan's characters were very distinctive. It refers to any female role in Peking opera. This type of character usually has a smart posture and a charming figure. During the performance, it can show the character's soft and delicate, light and flexible characteristics, which are very suitable for comics. A Kun Opera master Pai Yunsheng has summed up the image of "Dan" as 3 features: beautiful, lively, and veracious. In this study, the role of "Dan" in the opera was chosen as the sample, and the simplified expression of comics is adopted to make the comic closer to life and more intimate.

According to the four principles of "Transfer Features to Form", "Transform Features to Spirit", "Reflect Spirit to Semantics", and "Ignore Form to Essence", 4 photos from the characters in the opera were simplified and created. Figure 5 shows all 16 images after simplifying.

Table. 3 The Interpretation of the 4 performers and roles in Peking opera.

\begin{tabular}{ll}
\hline Performers and roles & Main content \\
The Sheng & $\begin{array}{l}\text { The Sheng is the main male role in Beijing opera. This role has numerous } \\
\text { subtypes. The laosheng is a dignified older role. These characters have a gen- } \\
\text { tle and cultivated disposition and wear sensible costumes. }\end{array}$ \\
\hline & $\begin{array}{l}\text { The Dan refers to any female role in Peking opera. Dan roles were originally } \\
\text { divided into five subtypes. Old women were played by laodan, martial } \\
\text { women were wudan, young female warriors were daomadan, virtuous and } \\
\text { elite women were qingyi, and vivacious and unmarried women were } \\
\text { huadan. }\end{array}$ \\
\hline The Jing & $\begin{array}{l}\text { The Jing is a painted face male role. Depending on the repertoire of the par- } \\
\text { ticular troupe, he will play either primary or secondary roles. This type of } \\
\text { role will entail a forceful character, so a Jing must have a strong voice and } \\
\text { be able to exaggerate gestures. Peking opera boasts } 16 \text { basic facial patterns, } \\
\text { but there are over } 100 \text { specific variations. }\end{array}$ \\
\hline & $\begin{array}{l}\text { The Chou is a male clown role. The Chou usually plays secondary roles in a } \\
\text { troupe. Indeed, most studies of Beijing opera classify the Chou as a minor } \\
\text { role. The name of the role is a homophone of the Mandarin Chinese word } \\
\text { chou, meaning "ugly". This reflects the traditional belief that the clown's } \\
\text { combination of ugliness and laughter could drive away evil spirits. }\end{array}$ \\
\hline
\end{tabular}




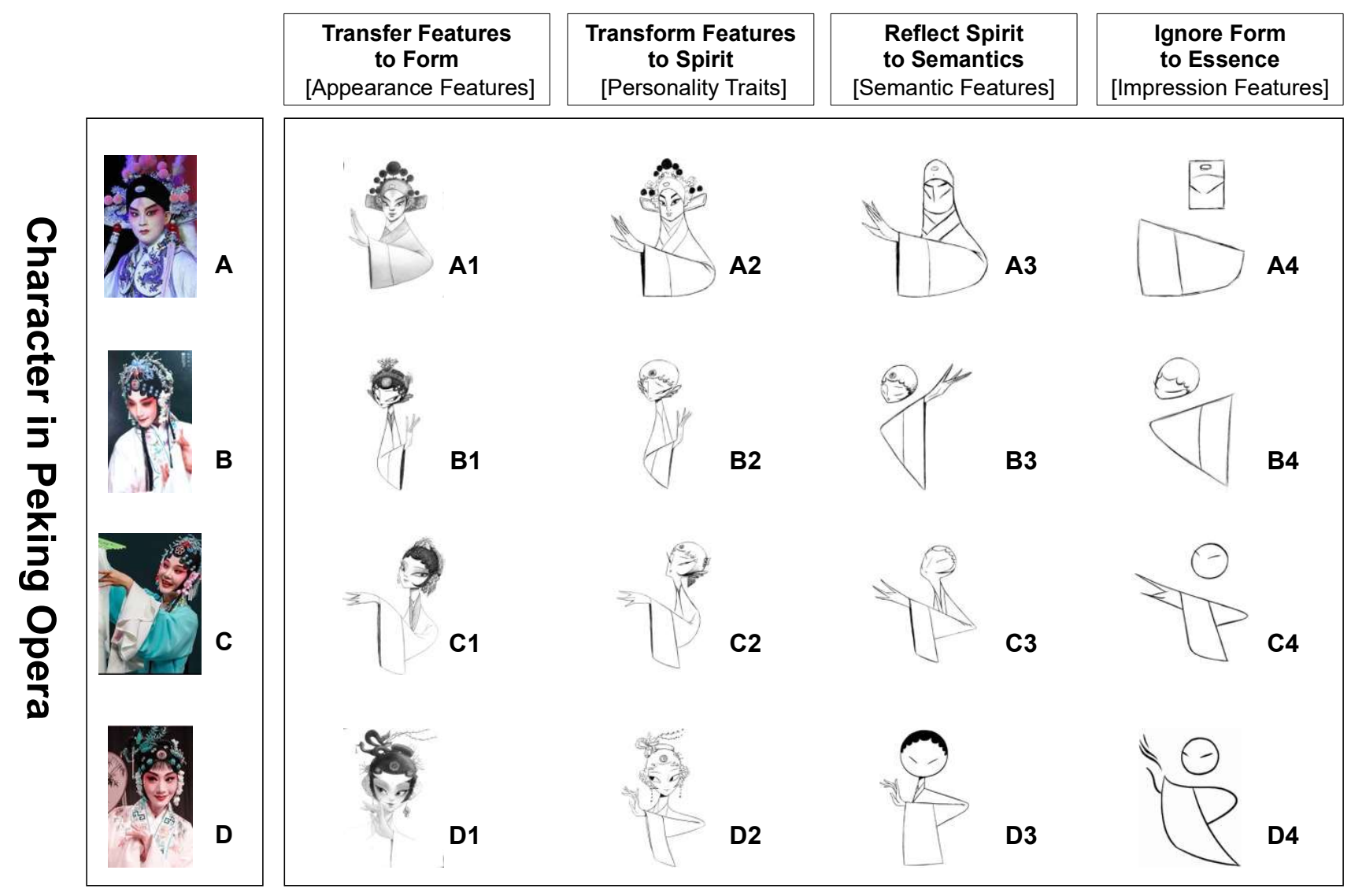

Figure 5. The samples and the four stages of simplification (Source: this study).

\subsection{Questionnaire}

This article is to explore how comic creation can be used to simplify the character of opera characters, and to study whether the viewer can understand the creator's motivation and ideas and assess the feasibility of such simplified creation [28,38,42]. This study proposes a two-stage evaluation method to design the questionnaire content. The first stage (the 1st part of the questionnaire) is Evaluation of Attribute. Participants need to evaluate the images of the 4 comic works in different simplified processes one by one according to the four evaluation attributes; the size of each image remains the same. A 5point Likert scale was utilized to score the responses from 1 ("Very unfit") to 5 ("Very fit"). The second stage (the 2nd and 3rd parts of the questionnaire) is the overall Evaluation of Preferences. For more details about the questionnaire, please see Appendix A. The questionnaire is drawn up in Chinese using Google forms, and the website address is: https://docs.google.com/forms/d/e/1FAIpQLScYd m9mSUyFEAOeOjF83pb1sdqFVNrS66r28MRz3tkgSgHhw/viewform?usp=sf link

\subsection{Participants}

The questionnaire was filled online. Within 48 hours, a total of 225 valid questionnaires were compiled. Participants in the distribution of gender, age, education, and background are shown in Table 4. Related research shows that it is generally recommended that the number of questionnaires should be 3-5 or 5-10 times the number of the most subscale questions in the test $[43,44,45]$. Therefore, the number of valid questionnaires recovered in this study meets the above requirements, and subsequent statistics and analysis can be performed. 
Table 4. Distribution of participants.

\begin{tabular}{|c|c|c|}
\hline Demographic Variables & & Num. (Prop.) \\
\hline \multirow{2}{*}{ 1. Gender } & Male & $89(39.6 \%)$ \\
\hline & Female & $136(60.4 \%)$ \\
\hline \multirow{4}{*}{ 2. Age } & $\leq 20$ & $78(34.7 \%)$ \\
\hline & $21-40$ & $69(30.7 \%)$ \\
\hline & $41-60$ & $71(31.6 \%)$ \\
\hline & $\geq 61$ & $7(3.1 \%)$ \\
\hline \multirow{3}{*}{ 3. Education } & University & $48(21.3 \%)$ \\
\hline & Graduate & $107(47.6 \%)$ \\
\hline & Other & $70(31.1 \%)$ \\
\hline \multirow{4}{*}{ 4. Background } & Design Related & $106(47.1 \%)$ \\
\hline & Art Related & $30(13.3 \%)$ \\
\hline & Social Science & $30(13.3 \%)$ \\
\hline & Natural Science & $59(26.2 \%)$ \\
\hline Total & 225 & \\
\hline
\end{tabular}

\section{Results and Discussion}

\subsection{Evaluation of Overall}

Based on the participants' responses, the average and standard deviation of the 16 samples from the 4 comics, and the ranking of the score in each question is shown in Table 5. These data can be used as a reference when further comparing the differences between different cases.

Table 5. The mean and standard deviation of the participant' responses to the 4 evaluation attributes and its ranking.

\begin{tabular}{|c|c|c|c|c|c|c|c|c|c|c|c|c|c|c|c|c|}
\hline & A1 & A2 & A3 & A4 & B1 & B2 & B3 & B4 & $\mathrm{C} 1$ & $\mathrm{C} 2$ & $\mathrm{C} 3$ & C4 & D1 & D2 & D3 & D4 \\
\hline \multirow{3}{*}{ Q1 } & 2.73 & 3.39 & 4.08 & 4.32 & 2.79 & 3.62 & 4.10 & 4.37 & 2.72 & 3.54 & 4.03 & 4.39 & 2.76 & 3.71 & 4.16 & 4.42 \\
\hline & 1.157 & 0.903 & 1.114 & 1.077 & 0.953 & 0.934 & 0.879 & 0.940 & 0.958 & 0.986 & 1.159 & 1.092 & 1.164 & 1.098 & 1.404 & 1.385 \\
\hline & \multicolumn{16}{|c|}{$\mathrm{D} 4>\mathrm{C} 4>\mathrm{B} 4>\mathrm{A} 4>\mathrm{D} 3>\mathrm{B} 3>\mathrm{A} 3>\mathrm{C} 3>\mathrm{D} 2>\mathrm{B} 2>\mathrm{C} 2>\mathrm{A} 2>\mathrm{B} 1>\mathrm{D} 1>\mathrm{A} 1>\mathrm{C} 1$} \\
\hline \multirow{3}{*}{ Q2 } & 4.14 & 3.30 & 2.33 & 2.07 & 4.30 & 3.60 & 3.21 & 2.36 & 4.29 & 3.60 & 2.81 & 2.08 & 4.45 & 3.93 & 2.58 & 2.38 \\
\hline & 1.118 & 0.794 & 0.904 & 0.942 & 0.853 & 0.917 & 0.865 & 0.890 & 0.951 & 1.039 & 1.036 & 1.081 & 1.045 & 1.098 & 1.254 & 1.250 \\
\hline & \multicolumn{16}{|c|}{$\mathrm{D} 1>\mathrm{B} 1>\mathrm{C} 1>\mathrm{A} 1>\mathrm{D} 2>\mathrm{C} 2>\mathrm{B} 2>\mathrm{A} 2>\mathrm{B} 3>\mathrm{C} 3>\mathrm{D} 3>\mathrm{D} 4>\mathrm{B} 4>\mathrm{A} 3>\mathrm{C} 4>\mathrm{A} 4$} \\
\hline \multirow{3}{*}{ Q3 } & 2.79 & 2.91 & 2.99 & 3.13 & 3.57 & 3.26 & 3.37 & 3.12 & 3.26 & 3.32 & 3.19 & 3.11 & 3.30 & 3.30 & 3.03 & 3.32 \\
\hline & 1.221 & 0.820 & 0.947 & 0.949 & 0.886 & 0.901 & 0.821 & 0.930 & 1.019 & 1.048 & 1.045 & 1.058 & 1.101 & 1.056 & 1.347 & 1.341 \\
\hline & \multicolumn{16}{|c|}{$\mathrm{B} 1>\mathrm{B} 3>\mathrm{D} 4>\mathrm{C} 2>\mathrm{D} 1>\mathrm{D} 2>\mathrm{B} 2>\mathrm{C} 1>\mathrm{C} 3>\mathrm{A} 4>\mathrm{B} 4>\mathrm{C} 4>\mathrm{D} 3>\mathrm{A} 3>\mathrm{A} 2>\mathrm{A} 1$} \\
\hline \multirow{3}{*}{ Q4 } & 3.00 & 3.02 & 3.00 & 3.16 & 3.62 & 3.35 & 3.39 & 3.02 & 3.39 & 3.36 & 3.19 & 3.01 & 3.54 & 3.49 & 3.08 & 3.32 \\
\hline & 1.360 & 0.749 & 1.033 & 1.048 & 0.917 & 0.884 & 0.837 & 0.887 & 0.890 & 1.020 & 1.056 & 1.064 & 1.054 & 1.147 & 1.294 & 1.335 \\
\hline & \multicolumn{16}{|c|}{$\mathrm{B} 1>\mathrm{D} 1>\mathrm{D} 2>\mathrm{B} 3>\mathrm{C} 1>\mathrm{C} 2>\mathrm{B} 2>\mathrm{D} 4>\mathrm{C} 3>\mathrm{A} 4>\mathrm{D} 3>\mathrm{A} 2>\mathrm{B} 4>\mathrm{C} 4>\mathrm{A} 3>\mathrm{A} 1$} \\
\hline
\end{tabular}

$(\mathrm{N}=225)$

Sorting out the number of votes for the nine questions on the second and third parts of the questionnaire (Table 6), the following characteristics can be found. Images of the different simplified processes of the comic-D won the highest recognition of all issues. However, the number of votes for the first place is not very high, most of them are concentrated on the 10 30\% interval, and the votes of other samples are also relatively close, indicating that there is no great consensus among the participants. In addition, most of the images acknowledged by the participants came from the first two stages of the simplified process. Only on a few issues were the most simplified samples select selected (e.g. D4). 
Table 6. Voting status of 9 questions in evaluation of preferences I \& II.

\begin{tabular}{|c|c|c|c|c|c|c|c|c|c|c|c|c|c|c|c|c|}
\hline \multicolumn{17}{|c|}{ 1. Which image is simplified to a most appropriate degree do you think? } \\
\hline Sample & D2 & D4 & B3 & $\mathrm{C} 2$ & B4 & A4 & $\mathrm{C} 3$ & D1 & $\mathrm{C} 4$ & B2 & A3 & A1 & D3 & A2 & $\mathrm{C} 1$ & B1 \\
\hline Votes & 43 & 29 & 23 & 20 & 17 & 13 & 13 & 13 & 12 & 11 & 9 & 6 & 6 & 5 & 3 & 2 \\
\hline Rates & 19.1 & 12.9 & 10.2 & 8.9 & 7.6 & 5.8 & 5.8 & 5.8 & 5.3 & 4.9 & 4 & 2.7 & 2.7 & 2.2 & 1.3 & 0.9 \\
\hline \multicolumn{17}{|c|}{ 2. Which image can best express the creativity? } \\
\hline Sample & $\mathrm{D} 4$ & D1 & B3 & $\mathrm{D} 2$ & B1 & $\mathrm{C} 2$ & $\mathrm{C} 3$ & B2 & D3 & $\mathrm{A} 4$ & $\mathrm{C} 4$ & A2 & $\mathrm{C} 1$ & A3 & B4 & A1 \\
\hline Votes & 58 & 24 & 23 & 20 & 18 & 13 & 12 & 11 & 9 & 8 & 8 & 6 & 6 & 4 & 3 & 2 \\
\hline Rates & 25.8 & 10.7 & 10.2 & 8.9 & 8 & 5.8 & 5.3 & 4.9 & 4 & 3.6 & 3.6 & 2.7 & 2.7 & 1.8 & 1.3 & 0.9 \\
\hline \multicolumn{17}{|c|}{ 3. Which image shows the richest elements of a cartoon? } \\
\hline Sample & D2 & D1 & B1 & B2 & D3 & $\mathrm{C} 2$ & $\mathrm{C} 1$ & A3 & $\mathrm{C} 3$ & $\mathrm{~A} 2$ & D4 & A1 & $\mathrm{A} 4$ & B3 & B4 & $\mathrm{C} 4$ \\
\hline Votes & 47 & 35 & 30 & 21 & 19 & 16 & 13 & 10 & 8 & 6 & 6 & 4 & 3 & 3 & 2 & 2 \\
\hline Rates & 20.9 & 15.6 & 13.3 & 9.3 & 8.4 & 7.1 & 5.8 & 4.4 & 3.6 & 2.7 & 2.7 & 1.8 & 1.3 & 1.3 & 0.9 & 0.9 \\
\hline \multicolumn{17}{|c|}{ 4. Which image has the best overall expression? } \\
\hline Sample & D1 & D2 & B1 & A1 & $\mathrm{C} 1$ & C2 & B2 & A2 & B3 & D4 & B4 & D3 & A3 & A4 & C3 & C3 \\
\hline Votes & 90 & 41 & 24 & 13 & 13 & 12 & 9 & 5 & 5 & 5 & 3 & 2 & 1 & 1 & 1 & 0 \\
\hline Rates & 40 & 18.2 & 10.7 & 5.8 & 5.8 & 5.3 & 4 & 2.2 & 2.2 & 2.2 & 1.3 & 0.9 & 0.4 & 0.4 & 0.4 & 0 \\
\hline \multicolumn{17}{|c|}{ 5. Which image you like best in terms of expression approach? } \\
\hline Sample & D1 & D2 & B1 & D4 & $\mathrm{C} 2$ & B2 & $\mathrm{C} 1$ & B3 & A1 & B4 & A2 & $\mathrm{C} 3$ & D3 & A3 & A4 & C4 \\
\hline Votes & 61 & 41 & 18 & 18 & 15 & 14 & 13 & 12 & 8 & 7 & 5 & 4 & 4 & 3 & 1 & 1 \\
\hline Rates & 27.1 & 18.2 & 8 & 8 & 6.7 & 6.2 & 5.8 & 5.3 & 3.6 & 3.1 & 2.2 & 1.8 & 1.8 & 1.3 & 0.4 & 0.4 \\
\hline
\end{tabular}

6. Which image do you think stresses the resemblance of "form" on the basis of form?

\begin{tabular}{lllllllllllllllll}
\hline Sample & D4 & D1 & A1 & D2 & B3 & A4 & C1 & C4 & A2 & A3 & B4 & B2 & C3 & B1 & D3 & D4 \\
Votes & 42 & 38 & 19 & 19 & 12 & 11 & 11 & 11 & 10 & 10 & 10 & 9 & 9 & 5 & 5 & 42 \\
Rates & 18.7 & 16.9 & 8.4 & 8.4 & 5.3 & 4.9 & 4.9 & 4.9 & 4.4 & 4.4 & 4.4 & 4 & 4 & 2.2 & 2.2 & 18.7 \\
\hline
\end{tabular}

7. Which image convey the spirit with the use of skillful techniques and emotional experience?

\begin{tabular}{lllllllllllllllll}
\hline Sample & D1 & D2 & C1 & B1 & B2 & A1 & C2 & B3 & D4 & B4 & A2 & A3 & D3 & C3 & A4 & C4 \\
Votes & 81 & 30 & 26 & 17 & 15 & 13 & 12 & 7 & 7 & 5 & 3 & 3 & 3 & 2 & 1 & 0 \\
Rates & 36 & 13.3 & 11.6 & 7.6 & 6.7 & 5.8 & 5.3 & 3.1 & 3.1 & 2.2 & 1.3 & 1.3 & 1.3 & 0.9 & 0.4 & 0 \\
\hline
\end{tabular}

8. Which image highlight the cultural characteristics by forming visual images of symbols through form and spirit?

\begin{tabular}{lllllllllllllllll}
\hline Sample & D1 & D4 & D2 & A1 & A2 & B1 & B3 & C1 & D3 & A4 & A3 & B4 & C2 & B2 & C3 & C4 \\
Votes & 39 & 35 & 27 & 20 & 14 & 12 & 11 & 10 & 10 & 9 & 8 & 8 & 8 & 6 & 5 & 3 \\
Rates & 17.3 & 15.6 & 12 & 8.9 & 6.2 & 5.3 & 4.9 & 4.4 & 4.4 & 4 & 3.6 & 3.6 & 3.6 & 2.7 & 2.2 & 1.3 \\
\hline
\end{tabular}

9. Which image reflects the conception and neglects the form and becomes an objective symbolic image?

\begin{tabular}{lllllllllllllllll}
\hline Sample & D4 & B4 & A4 & C4 & D1 & B3 & D3 & C1 & D2 & A1 & B2 & C3 & C2 & A2 & A3 & B1 \\
Votes & 69 & 26 & 25 & 18 & 13 & 12 & 10 & 8 & 8 & 7 & 6 & 6 & 5 & 4 & 4 & 3 \\
Rates & 30.7 & 11.6 & 11.1 & 8 & 5.8 & 5.3 & 4.4 & 3.6 & 3.6 & 3.1 & 2.7 & 2.7 & 2.2 & 1.8 & 1.8 & 1.3 \\
\hline
\end{tabular}
$(\mathrm{N}=225)$

However, images of different simplification stages of comic-D most recognized by the participants did not score very high on the attribute evaluation, and were mostly located in the middle and late stages. The individual evaluation of the four images of the simplification process may fail to grasp the simplification process as a whole, resulting in low recognition of individual images.

\subsection{Discussion}

The view and idea of simplified creation from the author were "Less is more, more is confused". It can be observed in the results that the audience's favorite images are not the ones that are most simplified. The participants' favorite images are from different simplification stages of comic-D, such as D4 (Figure 6). There was no requirement in the questionnaire for the participants to answer the simplified process of which groups of comics 

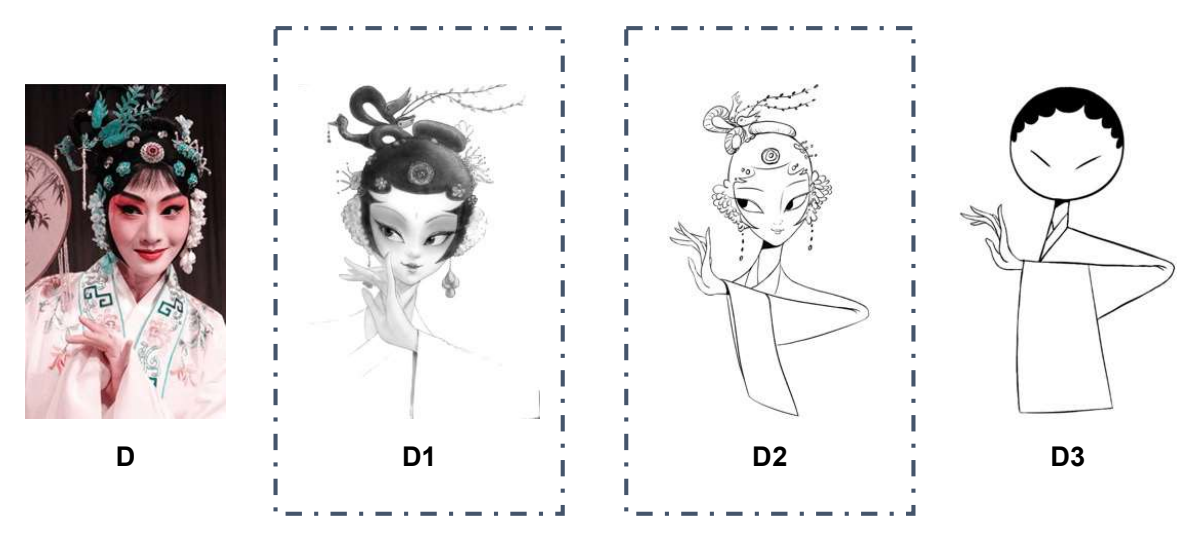
"Evaluation of Attribute" and "Evaluation of Preferences I \& II" are used for further discussion.

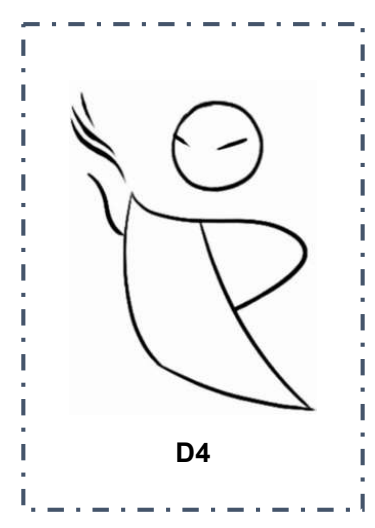

Figure 6. The most recognized sample in evaluation of preferences (Source: this study).

Table 7 shows the sample of the highest recognition of the 9 questions about the evaluation of preferences I \& II. D4 is the most simplified and tends to be symbolized. It almost discarded all the details and focused on the dynamics of the characters in the original work. Therefore, D4 has obtained the greatest recognition from the participants in terms of "Creative expression", "Form" and "Symbol". D1 and D2 are also most favored on other issues. For example, D4, A4, B4, and C4 are the most simplified images that tend to be symbolized. These samples can only be recognized by the participants on issues related to "shape", and the score and votes obtained in other evaluations are in the middle and lower positions. From the perspective of simplification, D2 received the highest recognition. It can be understood that it is not so simple that it is the most appropriate to be symbolized. However, the most simplified sample D4 has the most recognition in creative expression, which shows that the idea of "simplification" has a certain degree of creativity, but it needs further scrutiny on the degree of simplification.

Table 7. The sample that received the highest recognition in evaluation of preferences I \& II.

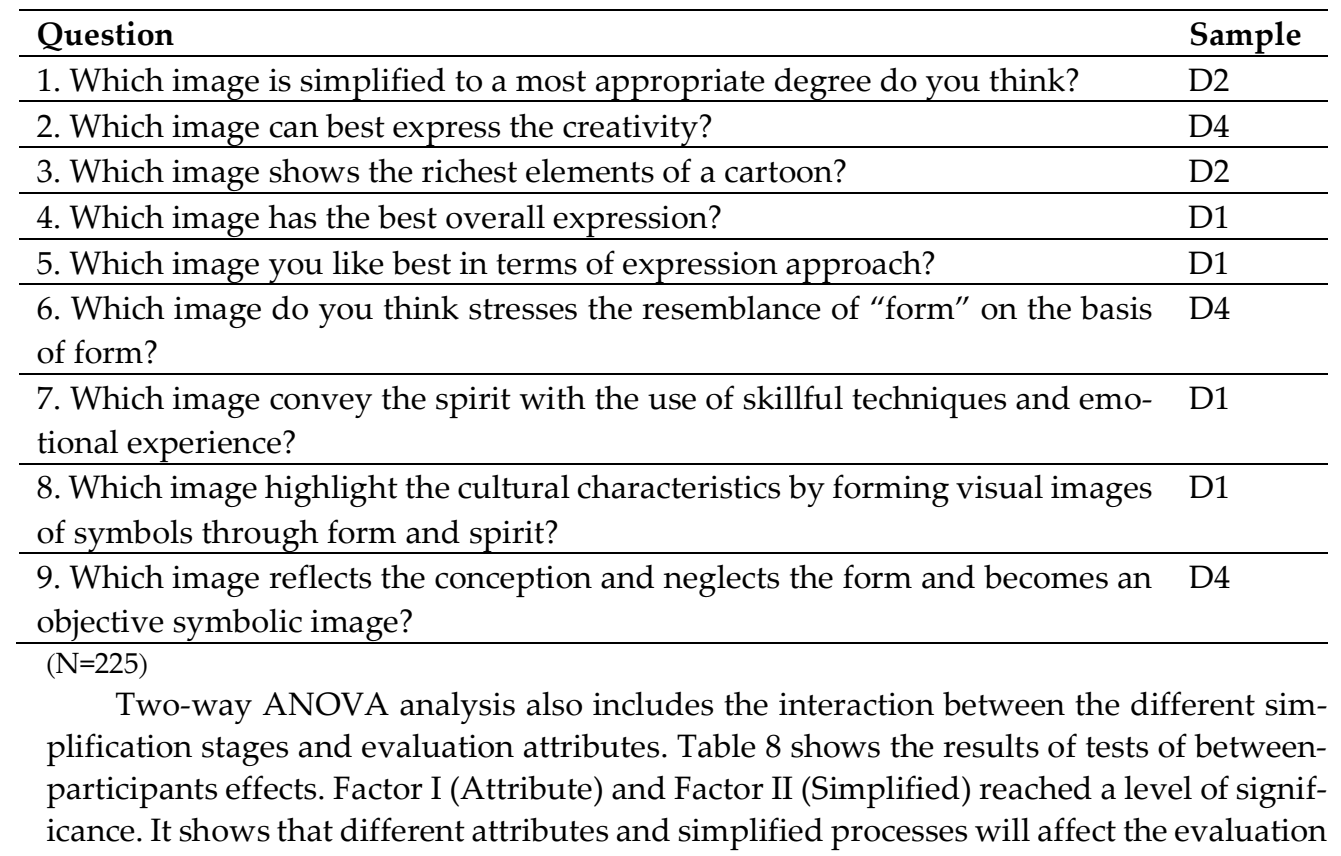


of the participants. Since the interaction between factor I and factor II also achieved a significant level $(F=101.936, p<.001)$, the simple main effect analysis was required (Table 9$)$.

Table 8. Tests of between-participants effects.

\begin{tabular}{llllll}
\hline Dependent Variable: Participant's evaluation & & & & \\
\hline Source & Type III Sum of Squares & $\mathrm{df}$ & $\begin{array}{l}\text { Mean } \\
\text { Square }\end{array}$ & $\mathrm{F}$ & Sig. \\
\hline Corrected Model & $1239.149 \mathrm{a}$ & 15 & 82.610 & $74.888^{* * *}$ & 0.000 \\
\hline Intercept & 42182.314 & 1 & 42182.314 & $38239.526^{* * *}$ & 0.000 \\
\hline Factor I & 81.559 & 3 & 27.186 & $24.645^{* * *}$ & 0.000 \\
\hline Factor II & 145.570 & 3 & 48.523 & $43.988^{* * *}$ & 0.000 \\
\hline Factor I ${ }^{*}$ Factor II & 1012.020 & 9 & 112.447 & $101.936^{* * *}$ & 0.000 \\
\hline Error & 3953.538 & 3584 & 1.103 & & \\
\hline Total & 47375.000 & 3600 & & & \\
\hline Corrected Total & 5192.686 & 3599 & & & \\
\hline R2 $=.239$ (Adjusted R2 $=.235) ;{ }^{* * *} p<0.001$ & & & &
\end{tabular}

Table 9. Summary of simple main effect.

\begin{tabular}{llllll}
\hline Source of Variable & Sum of Squares & df & Mean Square & F & Sig. \\
\hline Factor I- 4 attributes & & & & & \\
\hline Stage 1 & 335.587 & 3 & 111.862 & $97.760^{* * *}$ & .000 \\
\hline Stage 2 & 50.404 & 3 & 16.801 & $21.618^{* * *}$ & .000 \\
\hline Stage 3 & 302.209 & 3 & 100.736 & $98.787^{* * *}$ & .000 \\
\hline Stage 4 & 469.390 & 3 & 156.463 & $106.346^{* * *}$ & .000 \\
\hline Factor II- 4 stages of simplification & & & & & \\
\hline Attribute 1 & 356.093 & 3 & 118.698 & $103.354^{* * *}$ & .000 \\
\hline Attribute 2 & 695.932 & 3 & 231.977 & $250.907^{* * *}$ & .000 \\
\hline Attribute 3 & 13.337 & 3 & 4.446 & $3.900^{* *}$ & .009 \\
\hline Attribute 4 & 28.217 & 3 & 9.406 & $7.840^{* * *}$ & .000 \\
\hline$* * p<0.01,{ }^{* * *} p<0.001$ & & & & &
\end{tabular}

Factor I and II were controlled by "Simple main effect". The results show that both of them were clear differences. We can find specific differences by using One-way ANOVA analysis as described as following:

1. From different evaluation attributes, we can find: (1) In Attribute 1, there is not any difference between simplifying $3 \& 4$. The results of multiple comparisons between other groups were: II-2>II-1, II-3>II-1, II-4>II-1, II-2>II-3, and II-2>II-4. (2) In Attribute 2, there are differences in simplify $1 \& 3$, simplify $2 \& 3$, and simplify $2 \& 4$. The results of multiple comparisons between other groups were as follows: II-1>II-3, II-2>II-3, and II-2>II-4. (3) In Attribute 3, there is not any difference between simplify $3 \& 4$. The results of multiple comparisons between other groups were: II-1>II-2, II-1>II-3, II-1>II-4, II-3>II-2, and II-4>II-2. (4) In Attribute 3, there is not any difference between simplify $3 \& 4$. The results of multiple comparisons between other groups were: II-1>II-2, II-1>II-3, II-1>II-4, II-3>II-2, and II-4>II-2.

2. From different simplification stages, we can find: (1) In stage 1, there is no difference between attribute $3 \& 4$. The results of multiple comparisons between other groups were: I-2>I-1, I-3>I-1, I-4>I-1, I-3>I-2, and I-4>I-2. (2) In stage 2, there is no difference except between attribute $3 \& 4$. The results of multiple comparisons between other groups were: I-1>I-2, I-1>I-3, I-1>I-4, I-2>I-3, and I-2>I-4. (3) In stage 3 , the differences are only between attribute $1 \& 3$. The results of multiple comparisons between other groups were as follows: I-4>I-3. (4) In stage 4, there are differences in attributes $1 \& 3$, and attributes $2 \& 3$. The results of multiple comparisons between other groups were as follows: I-1>I-3, and I-2>I-3.

3. It can be seen from Figure 7 and Figure 8: (1) The images of the first two stages of simplification, except for the similar evaluation on the second attribute, there 
are big differences in the other three attributes. Nevertheless, the two images have a certain point of continuity, no matter how they are expressed or simplified, why such a large difference in cognition is worthy of further study. (2) The images of last two stages of simplification have very similar evaluations on all attributes, and there is not much fluctuation. In terms of details, the score of stage 4's image is comparatively high. The above results can explain: As far as the "simplification" itself is concerned, the participants' perception of the simplified image is relatively stable. However, they do not like images that are too simplified (close to symbols). This is in agreement with the results in Table 8.

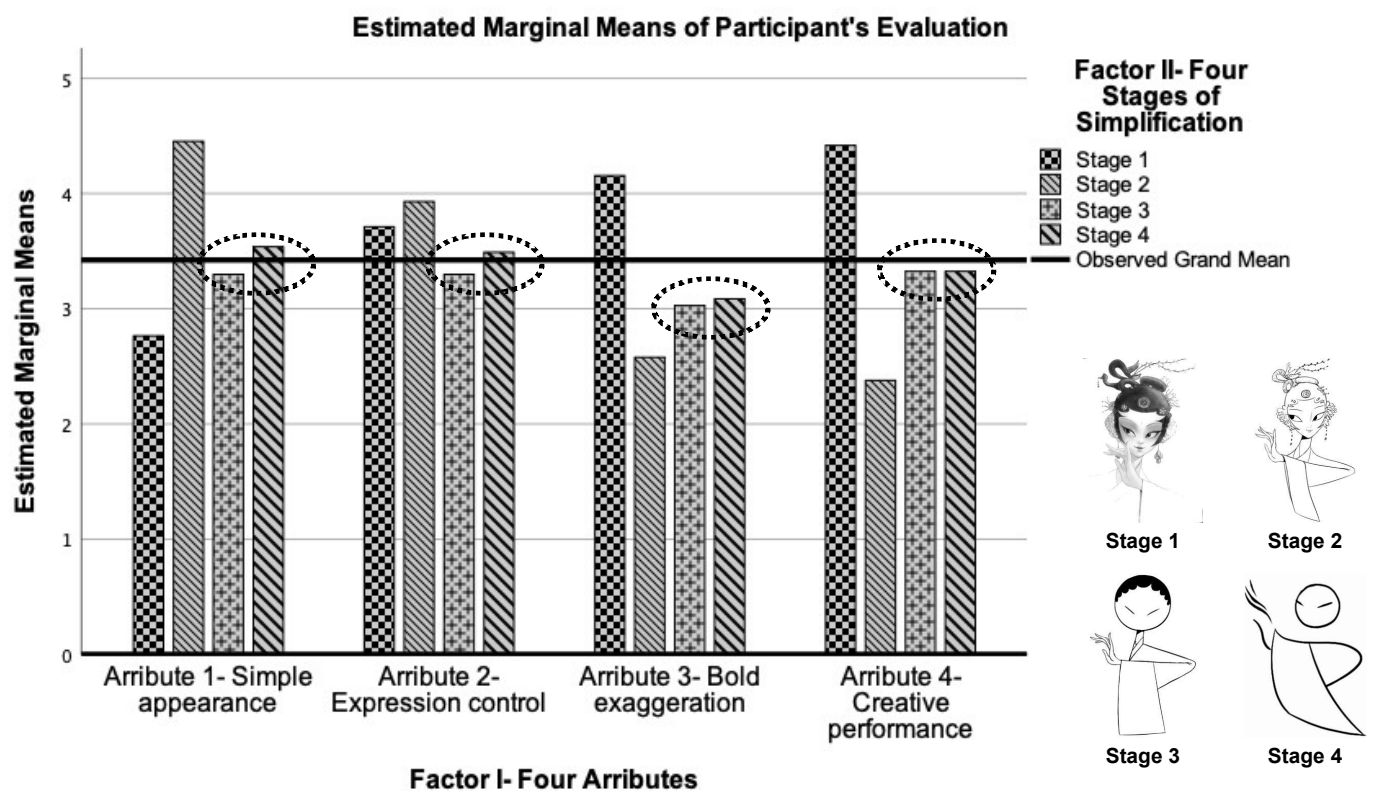

Figure 7. Profile plots of interaction between Factor I (Attribute) and Factor II (Simplified).

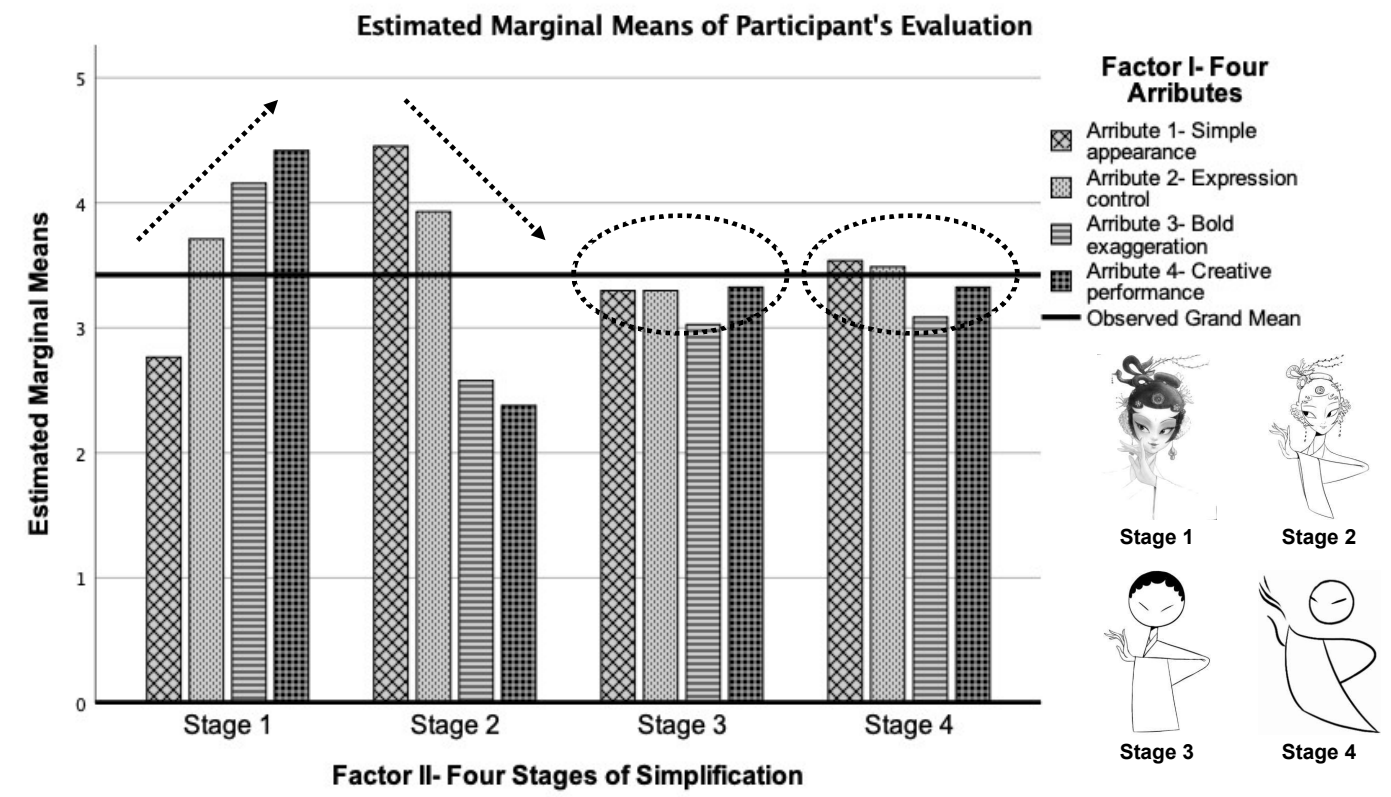

Figure 8. Profile plots of interaction between Factor II (Simplified) and Factor I (Attribute). 


\section{Conclusions and Suggestions}

This study is guided by the philosophical idea of "Less is more, more is confused" from ancient Chinese, and draws lessons from the creative thinking of Chinese traditional aesthetics. It used the four concepts "Transfer Features to Form", "Transform Features to Spirit", "Reflect Spirit to Semantics", and "Ignore Form to Essence" to construct a creative mode. We use comic expressions to simplify the characters in traditional opera to explore the feasibility and applicability of the author's construction model through a questionnaire survey and analysis to understand whether the audience agrees with this simplified creative mode. This creative idea and mode may provide a reference for other creators. From the feedback of the audience, the deficiencies in the creation mode and the communication process were reduced further. The conclusions of the study are as follows:

1. The viewers did not like images that have been simplified to the extreme which tended to be symbolic. They preferred samples that retain the main features of the original and have undergone artistic treatment with some simplification.

2. For the creators of this article, simplified creative ideas are feasible, but it is necessary to choose suitable and appropriate simplified processing methods according to different objects in order to let viewers understand the creator's intentions.

3. In this study, because of differences in gender, age, education and background of the viewers there will also be separate cognitive differences between them. This can be explored in future research. The audience of traditional opera is relatively certain, and may be mainly middle-aged and older people who like traditional culture. For creators and researchers, attracting the interest of other groups has become a very interesting and meaningful issue. Simplified imaginative thinking in the form of comics can play a role and it can also provide inspiration for other researchers.

The research always contains the following limitations and gaps, which will be completed and improved in the follow-up research. The related problems and solutions are as follows:

- The samples selected in this study have adopted the same simplified model and creative style. Participants may experience visual fatigue when answering outstanding questions. In future research, we may expand the size of the comparison group. Additionally, the author plans to add more characters from the Peking Opera to the research sample. This can reduce the cognitive limitations of a single sample type to better capture participant preferences and trends through comparison.

- The evaluation criteria of this article are jointly influenced by Chinese philosophy, Chinese calligraphy and painting theory and Ludwig Mies van der Rohe's modern design ideas. However, most respondents always use subjective intuition as the basis for their judgement. Therefore, it is not easy to explain the connotation of the artwork from a "scientific" perspective. Simplification is not the only way to "Less is more, more is confused", because simplification is a trade-off process. Future comic creators will need to consider how to reduce the details of the creation process, but still enable the audience to "get" the whole appearance of people. This also shows that the aim of this study is to simplify the application of the philosophy of "less is more, more is confused" in the creation of opera, which deserves further discussion and review.

To sum up, the body language of opera characters has undergone hundreds of years of evolution, which contains a high degree of refinement of beauty. In the creation of comics, in addition to the vivid depiction of the characters, the overall effect of the image and the aesthetic experience of the viewer must also be considered. We should let the audience feel the content of the external comic image, and at the same time, also taste the formal aesthetic feeling of the comical shapes. For creators, it is necessary to pick out an appropriate form to express opera elements so that the audience can understand the creator's creative intentions. In future research, it is necessary to further research the relationship between the creator's thinking and the audience's cognition. The framework and cognitive 
model of the integration of traditional opera and modern comics proposed in this article can also be further improved (Figure 9).

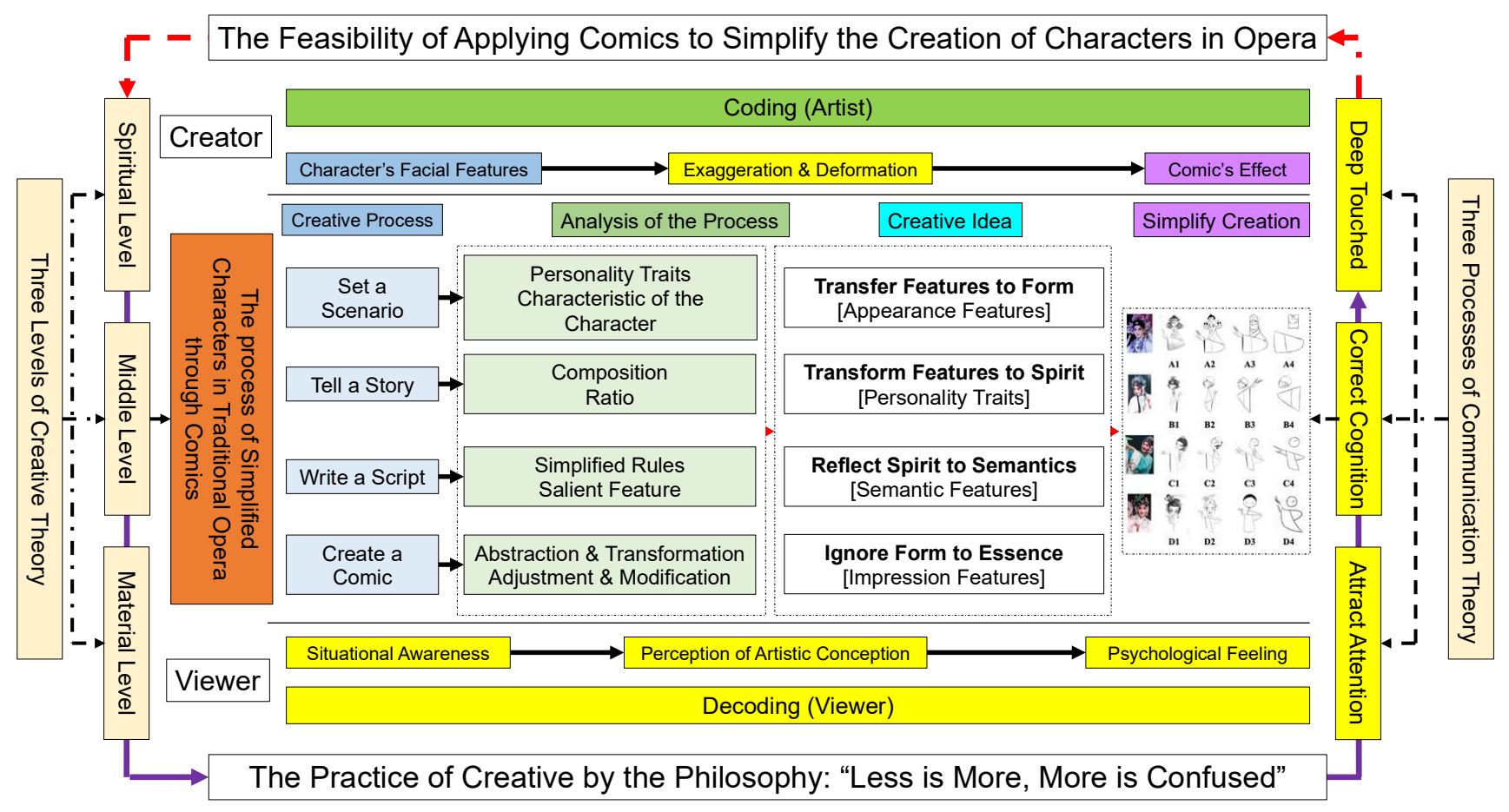

Figure 9. The Framework of Future Research (Source: this study)

Author Contributions: Data curation, Writhing - review \& editing, R.L.; Resources, J.W.; Writingoriginal draft, Y.S. All authors have read and agreed to the published version of the manuscript.

Funding: This research received no external funding.

Data Availability Statement: The authors confirm that the data supporting the findings of this study are available within the article.

Conflicts of Interest: The author declares no conflict of interest.

\section{Appendix A}

\section{Part 1: Evaluation of attribute}

Based on the following 4 attributes, please subjectively evaluate the strength of the attributes corresponding to each work in the four stages of each comic work in the simplified process.

Here are 4 sets of comics in total, and each set of comic has 4 images in different simplified processes. Every image needs to be answered the same questions from 4 attributes.

Sample and the four stages of simplification Evaluation attributes and scoring standard

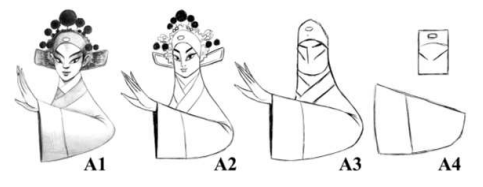

1. Simple appearance

2. Expression control

3. Bold exaggeration

4. Creative performance
Very unfit $\square 1 \square 2 \square 3 \square 4 \square 5$ Very fit Very unfit $\square 1 \square 2 \square 3 \square 4 \square 5$ Very fit Very unfit $\square 1 \square 2 \square 3 \square 4 \square 5$ Very fit Very unfit $\square 1 \square 2 \square 3 \square 4 \square 5$ Very fit 


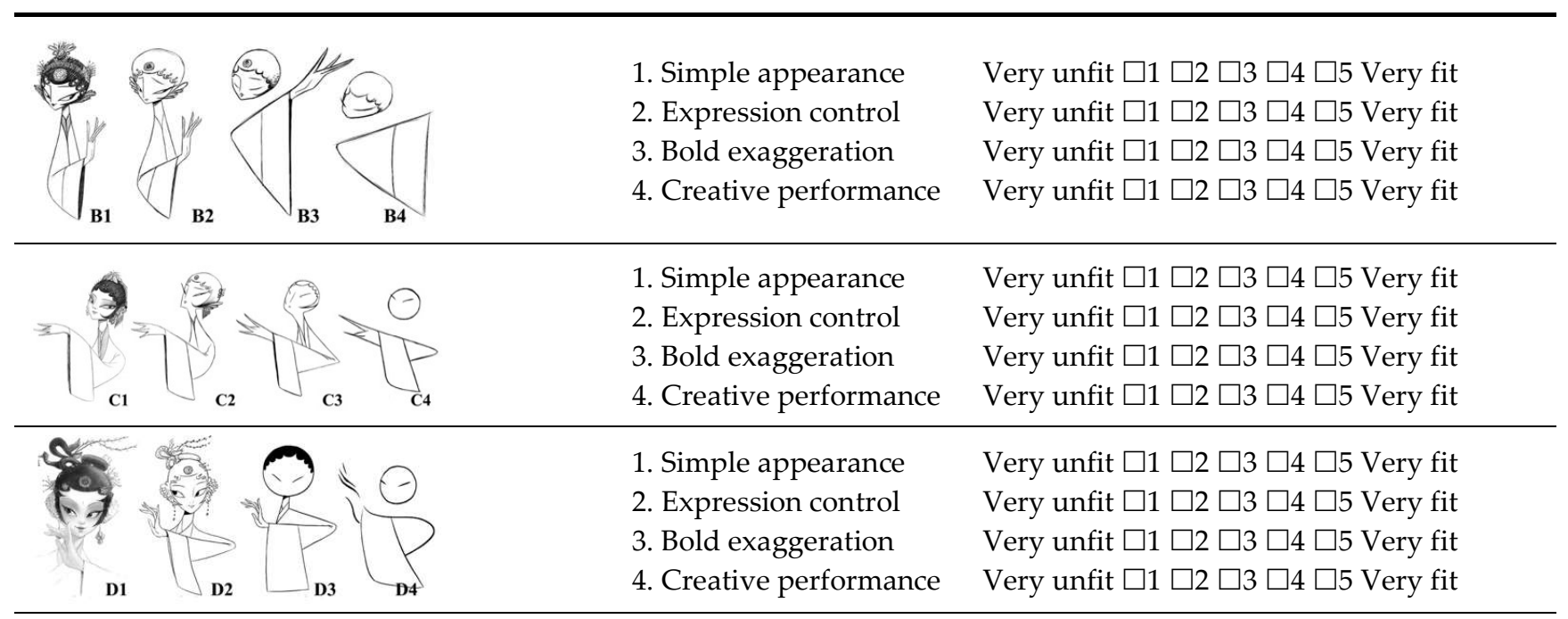

Part 2 \& 3: Evaluation of preferences I \& II

Based on the following 9 questions, select the image you think is most suitable.

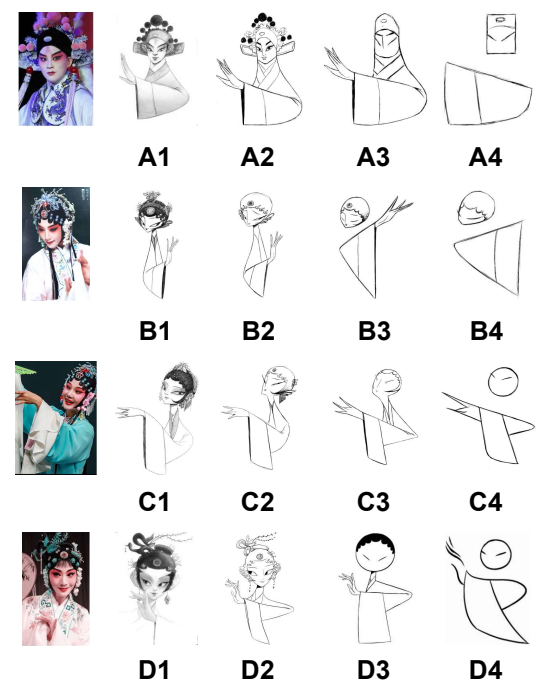

\section{Evaluation of preferences I}

1. Which image is simplified to a most appropriate degree do you think?

$\square \mathrm{A} 1 \quad \square \mathrm{A} 2 \quad \square \mathrm{A} 3 \quad \square \mathrm{A} 4 \quad \square \mathrm{B} 1 \quad \square \mathrm{B} 2 \quad \square \mathrm{B} 3 \quad \square \mathrm{B} 4$

2. Which image can best express the creativity?

$\square \mathrm{A} 1 \quad \square \mathrm{A} 2 \quad \square \mathrm{A} 3 \quad \square \mathrm{A} 4 \quad \square \mathrm{B} 1 \quad \square \mathrm{B} 2 \quad \square \mathrm{B} 3 \quad \square \mathrm{B} 4$

$\square \mathrm{C} 1 \quad \square \mathrm{C} 2 \quad \square \mathrm{C} 3 \quad \square \mathrm{C} 4 \quad \square \mathrm{D} 1 \quad \square \mathrm{D} 2 \quad \square \mathrm{D} 3 \quad \square \mathrm{D} 4$

3. Which image shows the richest elements of a cartoon?

$\square \mathrm{A} 1 \quad \square \mathrm{A} 2 \quad \square \mathrm{A} 3 \quad \square \mathrm{A} 4 \quad \square \mathrm{B} 1 \quad \square \mathrm{B} 2 \quad \square \mathrm{B} 3 \quad \square \mathrm{B} 4$

$\square \mathrm{C} 1 \quad \square \mathrm{C} 2 \quad \square \mathrm{C} 3 \quad \square \mathrm{C} 4 \quad \square \mathrm{D} 1 \quad \square \mathrm{D} 2 \quad \square \mathrm{D} 3 \quad \square \mathrm{D} 4$

4. Which image has the best overall expression?

$\square \mathrm{A} 1 \quad \square \mathrm{A} 2 \quad \square \mathrm{A} 3 \quad \square \mathrm{A} 4 \quad \square \mathrm{B} 1 \quad \square \mathrm{B} 2 \quad \square \mathrm{B} 3 \quad \square \mathrm{B} 4$

$\square \mathrm{C} 1 \quad \square \mathrm{C} 2 \quad \square \mathrm{C} 3 \quad \square \mathrm{C} 4 \quad \square \mathrm{D} 1 \quad \square \mathrm{D} 2 \quad \square \mathrm{D} 3 \quad \square \mathrm{D} 4$

5. Which image you like best in terms of expression approach?
$\square \mathrm{A} 1 \quad \square \mathrm{A} 2 \quad \square \mathrm{A} 3 \quad \square \mathrm{A} 4 \quad \square \mathrm{B} 1 \quad \square \mathrm{B} 2 \quad \square \mathrm{B} 3 \quad \square \mathrm{B} 4$

$\square \mathrm{C} 1 \quad \square \mathrm{C} 2 \quad \square \mathrm{C} 3 \quad \square \mathrm{C} 4 \quad \square \mathrm{D} 1 \quad \square \mathrm{D} 2 \quad \square \mathrm{D} 3 \quad \square \mathrm{D} 4$

Evaluation of preferences II

6. Which image do you think stresses the resemblance of "form" on the basis of form?
$\square \mathrm{A} 1 \quad \square \mathrm{A} 2 \quad \square \mathrm{A} 3 \quad \square \mathrm{A} 4 \quad \square \mathrm{B} 1 \quad \square \mathrm{B} 2 \quad \square \mathrm{B} 3 \quad \square \mathrm{B} 4$
$\square \mathrm{C} 1 \quad \square \mathrm{C} 2 \quad \square \mathrm{C} 3 \quad \square \mathrm{C} 4 \quad \square \mathrm{D} 1 \quad \square \mathrm{D} 2 \quad \square \mathrm{D} 3 \quad \square \mathrm{D} 4$

7. Which image convey the spirit with the use of skillful techniques and emotional experience?
$\square \mathrm{A} 1 \quad \square \mathrm{A} 2 \quad \square \mathrm{A} 3 \quad \square \mathrm{A} 4 \quad \square \mathrm{B} 1 \quad \square \mathrm{B} 2 \quad \square \mathrm{B} 3 \quad \square \mathrm{B} 4$
$\square \mathrm{C} 1 \quad \square \mathrm{C} 2 \quad \square \mathrm{C} 3 \quad \square \mathrm{C} 4 \quad \square \mathrm{D} 1 \quad \square \mathrm{D} 2 \quad \square \mathrm{D} 3 \quad \square \mathrm{D} 4$

8. Which image highlight the cultural characteristics by forming visual images of symbols through form and spirit?
$\square \mathrm{A} 1 \quad \square \mathrm{A} 2 \quad \square \mathrm{A} 3 \quad \square \mathrm{A} 4 \quad \square \mathrm{B} 1 \quad \square \mathrm{B} 2 \quad \square \mathrm{B} 3 \quad \square \mathrm{B} 4$
$\square \mathrm{C} 1 \quad \square \mathrm{C} 2 \quad \square \mathrm{C} 3 \quad \square \mathrm{C} 4 \quad \square \mathrm{D} 1 \quad \square \mathrm{D} 2 \quad \square \mathrm{D} 3 \quad \square \mathrm{D} 4$

9. Which image reflects the conception and neglects the form and becomes an objective symbolic image?

$\square \mathrm{A} 1 \quad \square \mathrm{A} 2 \quad \square \mathrm{A} 3 \quad \square \mathrm{A} 4 \quad \square \mathrm{B} 1 \quad \square \mathrm{B} 2 \quad \square \mathrm{B} 3 \quad \square \mathrm{B} 4$ $\square \mathrm{C} 1 \quad \square \mathrm{C} 2 \quad \square \mathrm{C} 3 \quad \square \mathrm{C} 4 \quad \square \mathrm{D} 1 \quad \square \mathrm{D} 2 \quad \square \mathrm{D} 3 \quad \square \mathrm{D} 4$ 


\section{References}

1. Krohn, C. Mies van der Rohe: The Built Work; Birkhäuser Verlag AG: Basel, Switzerland, 2014.

2. Puente, M. Conversations with Mies van der Rohe. Princeton Architectural Press: New York, NY, USA, 2008.

3. Schulze, F. Mies van der Rohe: A Critical Biography; University of Chicago Press: Chicago, IL, USA, 1989.

4. Browning, R. Andrea del Sarto. Available online: https://www.poetryfoundation.org/poems/43745/andrea-del-sarto (accessed on 21 March 2021)

5. Hohne, K. The Essential I Ching: 64 Degrees of Nature's Wisdom; Way of Tao Books: Carnelian Bay, CA. USA, 2015.

6. Chernev, A. When More is Less and Less is More: The Role of Ideal Point Availability and Assortment in Consumer Choice. J. Consum. Res. 2003, 30(2), 170-183. doi:10.1086/376808

7. Conrads, U., Ed. Programs and Manifestoes on 20th-century Architecture (pp. 74-75); The MIT Press: Cambridge, MA, USA, 1970.

8. Greenough, H. Form and Function: Remarks on Art, Design, and Architecture; University of California Press: Berkeley, CA, USA, 1947.

9. Ayanoğlu, H.; Duarte, E. Emotional Design in Human-robot Interaction: Theory, Methods and Applications; Springer: Cham, Switzerland, 2019.

10. Hekkert, P.; Leder, H. Product Aesthetics. In Product Experience (pp. 259-286); Schifferstein, H.N.J.; Hekkert, P., Eds., Elsevier: San Diego, CA, USA, 2008.

11. Hekkert, P.; Snelders, D.; Wieringen, P. C. 'Most advanced, yet acceptable': Typicality and Novelty as Joint Predictors of Aesthetic Preference in Industrial Design. Br J Psychol 2003, 94(1), 111-124. doi:10.1348/000712603762842147

12. Helander, M.G.; Po Tham, M. Hedonomics- affective Human Factors Design. Ergon, 2003, 46(13-14), 1269-1272. doi:10.1080/00140130310001610810

13. Norman, D.A. Emotional Design: Why We Love (or Hate) Everyday Things; Basic Book: New York, NY, USA, 2004.

14. Schenker, M. The Minimalist Design Trend: Why Less is More. Available online: https://creativemarket.com/blog/minimalistdesign-trend (accessed on 20 March 2021)

15. Norton, M.I.; Frost, J.H.; Ariely, D. Less is More: The Lure of Ambiguity, or Why Familiarity Breeds Contempt. J Pers Soc Psychol 2007, 92(1), 97-105. doi:10.1037/0022-3514.92.1.97

16. Ayu, P. Designing Caricature in Teaching Writing for EFL Learners. Research in English and Education Journal, 2016, 1(1), 1-9.

17. Browne, J.E. Darwin in Caricature: A Study in the Popularisation and Dissemination of Evolution. Proceedings of the American Philosophical Society, 2001, 145(4), 496-509.

18. Medley, S. Discerning Pictures: How We Look at and Understand Images in Comics. Studies in Comics, 2010, 1(1), 53-70. doi:10.1386/stic.1.1.53/1

19. Lin, R. A Study of Nature Form for Basic Design Instruction. J. Technol. 1987, 2(1), 17-24.

20. Meyer, R.P.; Laveson, J.I.; Puls, D. An Experience-Judgement Approach to Tactical Flight Training. Proceedings of the Human Factors Society Annual Meeting, 1981, 25(1), 657-660. doi:10.1177/1071181381025001173

21. Lin, R. A Study of Visual Features for Icon Design. Design Studies, 1994, 15(2), 185-197. doi:10.1016/0142-694x(94)90024-8

22. Washburn, D. K. Structure and Cognition in Art; Cambridge University Press: Cambridge, MA, USA, 1983.

23. Wang, R.W.; Hsu, C.C. Study of the Design Operation of Graphic Simplification. The Design Journal, 2007, 10(3), 54-75. doi:10.2752/146069207789271894

24. Wang, R.W.; Hsu, C.C. The Method of Graphic Abstraction in Visual Metaphor. Visible Language, 2007, 41(3), $284-297$.

25. Hsu, C.C.; Wang, R.W. The Relationship Between Shape Features and Degrees of Graphic Simplification. Journal of Design, 2010, 15(3), 87-105.

26. Papanek, V. Design for the Real World; Academy Chicago Publishers. Chicago, IL, USA, 1985.

27. Chugh, A. Importance of Communication in the Design Process. Available online: https://uxdesign.cc/importance-of-communication-in-the-design-process-b686b5885623 (accessed on 21 March 2021)

28. Lin, R.; Qian, F.D.; Wu, J.; Fang, W.T.; Jin, Y.G. A Pilot Study of Communication Matrix for Evaluating Artworks. Cross-Cultural Design, 2017, 356-368. doi:10.1007/978-3-319-57931-3_29

29. Bai, Q.S. Image as Word: A Study of Rebus Play in Song Painting (960-1279). Metropolitan Museum Journal, 1999, 34, 12+57-72. doi:10.2307/1513046

30. Murch, A. Words in Chinese Painting. In A companion to Chinese Art (pp. 457-474); Powers, M.J.; Tsiang, K.R., Eds.; John Wiley \& Sons: Hoboken, NJ, USA, 2015.

31. Silbergeld, J. Chinese Concepts of Old Age and Their Role in Chinese Painting, Painting Theory, and Criticism. Art J. 1987, 46(2), 103-114. doi:10.2307/776887

32. Dillon, M. Ed., China: A Cultural and Historical Dictionary; Curzon Press: London, UK, 1998.

33. Binyon, L. The Flight of the Dragon: An Essay on the Theory and Practice of Art in China and Japan, Based on Original Sources. John Murray: London, UK, 1911.

34. Briessen, F.V. The Way of the Brush: Painting Techniques of China and Japan. Tuttle: Rutland, UK, 1962.

35. Craig, R.T. Communication Theory as a Field. Commun Theory 1999, 9(2), 119-161. doi:10.1111/j.1468-2885.1999.tb00355.x

36. Fiske, J. Introduction to Communication Studies; Routledge: London, UK, 2010.

37. Jakobson, R. Language in Literature; Harvard University Press: Cambridge, MA. USA, 1987. 
38. Lin, R. Transforming Taiwan Aboriginal Cultural Features into Modern Product Design: A Case Study of a Cross-cultural Product Design Model. Int. J. Des., 2007, 1(2), 45-53.

39. Goldstein, J. Mei Lanfang and the Nationalization of Peking Opera, 1912-1930. East Asian Cult. Crit. 1999, 7(2). 377-420. doi:10.1215/10679847-7-2-377

40. Halson, E. Peking Opera: A Short Guide; Oxford University Press: Oxford, UK, 1966.

41. Wikipedia. Peking Opera. Available online: https://en.wikipedia.org/wiki/Peking_opera\#Performers_and_roles (accessed on 2 April 2021)

42. Lin, C.L.; Chen, J.L.; Chen, S.J.; Lin, R. The Cognition of Turning Poetry into Painting. Journal of US-China Education Review B, 2015, 5(8), 471-487. doi:10.17265/2161-6248/2015.08b.001

43. Comrey, A.L. Factor-analytic Methods of Scale Development in Personality and Clinical Psychology. J Consult Clin Psychol 1988, 56(5), 754-761. doi:10.1037/0022-006x.56.5.754

44. Tinsley, H.E.; Tinsley, D.J. Uses of Factor Analysis in Counseling Psychology Research. Couns Psychol, 1987, 34(4), 414-424. doi:10.1037/0022-0167.34.4.414

45. Wu, M. L.; Tu, J.T. SPSS \& the Application and Analysis of Statistics; Wu-Nan Book Inc.: Taipei, 2011. 